\title{
Editorial
}

\section{Research and Respect}

The Association of College and Research Libraries' (ACRL) National Conference, "Continuity \& Transformation: The Promise of Confluence" attracted a lively assortment of papers, poster sessions, conference speakers, and colleagueto-colleague discussions. This editorial recounts two related concerns: the state of research in librarianship and the issue of respect. In these areas and others, librarians must rethink priorities and commit themselves anew to action.

\section{RESEARCH}

Larry Oberg, College and Research Libraries Research Notes editor, and I participated with John Berry III of Library Journal and Library Hotline, GraceAnne DeCandido of Wilson Library Bulletin, and Patricia Glass Schuman of Neal Schuman Publishers in a McLaughlinstyle panel moderated by James Neal to discuss "Library Publishing in the 90s: Future Generations Will Ask ...." The panel agreed that less research is being produced than is needed to meet future decision-making requirements. All perceive that librarianship is changing rapidly and that the need for factual information upon which to base decisions has never been greater. Nevertheless, the pressures of everyday service during times of shrinking budgets and the continuing need to learn new technologies have reduced the production of research-based articles. From the audience, Don Riggs of the University of Michigan noted that 30.3 percent of the papers presented at the ACRL conference in 1978 were research-based. However, since 1978, the percentage of research-based papers pre- sented at ACRL conferences has declined dramatically.

Because the formal scholarly publication system is slow and because the pace of change is fast, the panel discussed the place of listservs in an evolving scholarship communications system. GraceAnne DeCandido and her staff regularly review listservs for promising ideas. Authors are then contacted and ideas are developed into articles suitable for publication in Wilson Library Bulletin. Larry Oberg, who moderates the COLLIB-L list, believes that such lists encourage both a practical and theoretical dialogue within college librarianship, a dialogue that would supplement our published literature and allow for the continuation of discussions begun at associated conferences and professional workshops. John Berry emphasized that the lack of refereeing, reviewing, and editing makes this format a poor substitute for a traditional discipline literature.

Librarians can start producing a more vital research literature by undertaking three incremental steps. First, promotion and tenure committees and administrators who evaluate both faculty and nonfaculty librarians should focus on quality rather than quantity. An article employing a rigorous research methodology should receive significantly more credit than a case study. Second, library administrators must set aside modest amounts of money to support research projects. Librarians must design the studies, but money should be available for expenses, such as statistical assistance, data entry, and questionnaire mailings. Third, librarians must organize formal and informal collegial forums 
to discuss ideas, to sharpen research topics, and to review manuscripts.

\section{RESPECT}

\section{Scholar Librarian}

In the "Introduction" to the Summer 1994 Library Trends issue on library directors, Irene B. Hoadley says, "The scholar librarian is really a concept of the past."* With so much emphasis being placed on leading the library in a complex external environment, shifting to a professional administrator, instead of a faculty member, making campus policy, and expanding development activities, the time available for scholarship has been reduced. On campuses everywhere, these same factors are changing the roles of deans in all colleges. Thus, not only is the time of the scholar librarian passing but also that of the scholar, dean, provost, and president.

Having librarians with doctorates in other disciplines was a method for gaining respect from other faculty on campus. Through years of reliable work with faculty and students, the library has achieved an enviable reputation among many faculty as a central part of the academy. To maintain this campus position, library deans and directors must provide vision, inspiration, and direction in an increasingly complex environment. This means developing and maintaining ongoing dialogue and partnerships with faculty and administrators across campus.

\section{Paraprofessionals}

Empowering library staff to participate more fully in the library is an important trend. Its advantages include better and quicker decision making on process issues, a more diverse input to problem resolution, and freeing librarians to develop new initiatives in instruction, service, and research. Researchers such as Larry Oberg report increased blurring between professional and paraprofessional/staff roles.

Unlike the issue over faculty status, where both sides are well matched and have carried on a rigorous public discussion, the issues between librarians and library staff have not been openly and honestly presented. Library staff, who are even less socialized to the scholarly process than librarians, have summarized their aspirations into a call for respect. Library staff want recognition for the value of the work performed. In most libraries, staff handle critical routine functions that are essential to smooth operations and that involve sensitive interactions with library users. Staff want the value of this work acknowledged. In addition, staff do not want to be treated disrespectfully just because they don't have a master's degree in librarianship. It would be helpful to know what other issues are sheltered beneath that short word "respect." Many new techniques, such as decision centers where computers allow individuals to participate equally without regard for rank, are now available. A study that explores this subject would make a highly desirable addition to the literature of librarianship.

Research and respect converge here. Trusting library staff to administer many library functions frees up librarian time for more research. Creating a meaningful literature to guide our decision making, providing vision and inspiration for librarians, and improving the working relationships within the library are some achievable results that can yield a brighter future.

The editor wishes to thank Karyle Butcher and Larry Oberg for their assistance with this editorial.

GLORIANA ST. CLAIR

* Irene B. Hoadley, "Introduction," Library Trends 43 (Summer 1994): 8. 


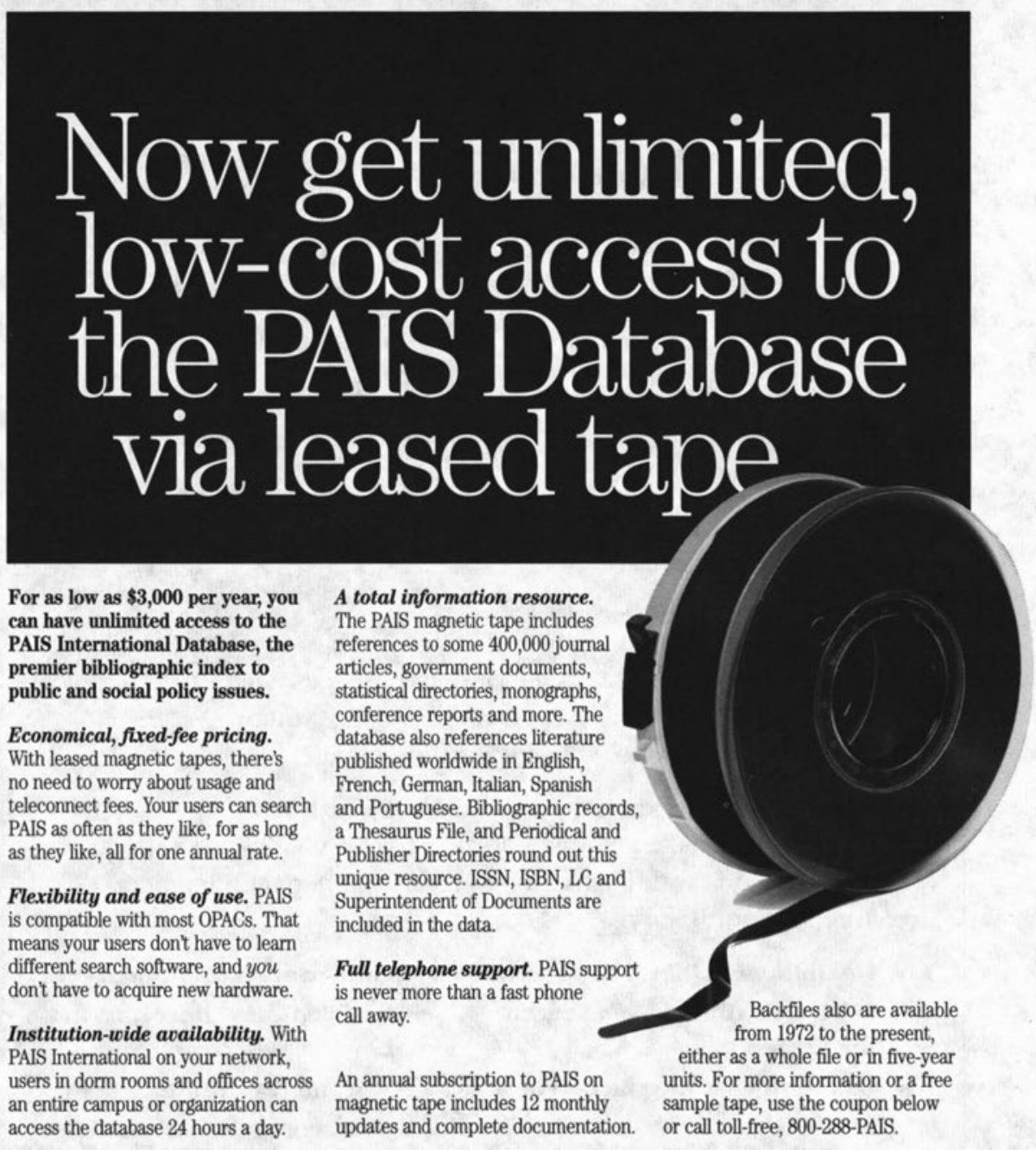




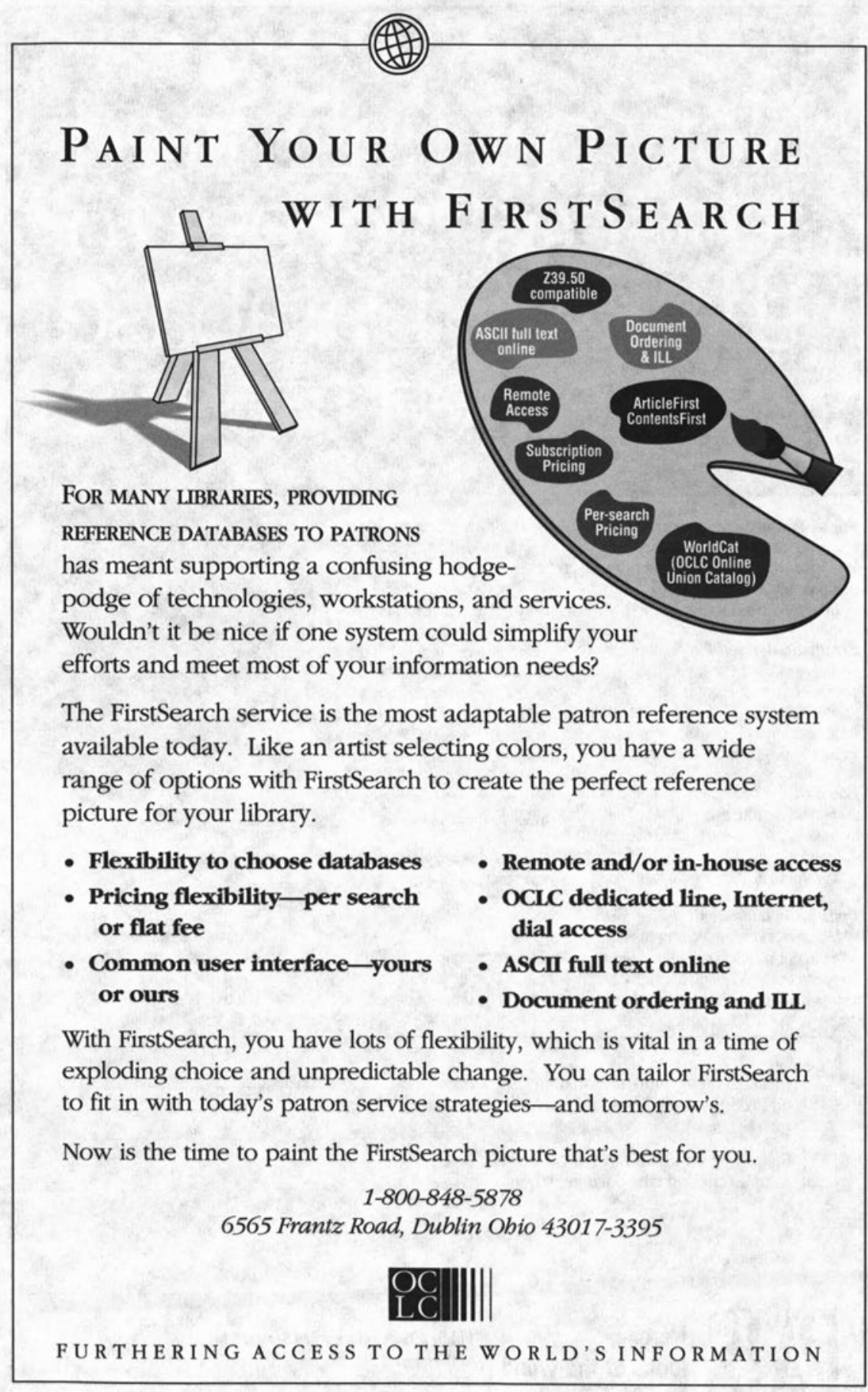

